\title{
Brazilian Angiostrongylus cantonensis haplotypes, ac8 and ac9, have two different biological and morphological profiles
}

\author{
Tainá CC Monte', Rosana Gentile', Juberlan Garcia', Ester Mota ${ }^{2}$, \\ Jeannie N Santos ${ }^{3}$, Arnaldo Maldonado Júnior¹/+
}

'Laboratório de Biologia e Parasitologia de Mamíferos Silvestres Reservatórios ²Laboratório de Patologia, Instituto Oswaldo Cruz-Fiocruz, Rio de Janeiro, RJ, Brasil ${ }^{3}$ Laboratório de Biologia Celular e Helmintologia Profa

Instituto de Ciências Biológicas, Universidade Federal do Pará, Belém, PA, Brasil

Angiostrongylus cantonensis is the etiologic agent of eosinophilic meningoencephalitis in humans. Cases have been recorded in many parts of the world, including Brazil. The aim of this study was to compare the differences in the biology and morphology of two different Brazilian haplotypes of A. cantonensis: ac8 and ac9. A significantly larger number of L1 larvae eliminated in the faeces of rodents at the beginning of the patent period was observed for ac 9 haplotype and compared to the total of L1 larvae eliminated, there was a significant difference between the two haplotypes. The ac9 haplotype showed a significant difference in the proportion of female and male specimens (0.6:1), but the same was not observed for ac8 (1.2:1). The morphometric analysis showed that male and female specimens isolated from ac8 haplotype were significantly larger with respect to body length, oesophagus length, spicule length (male) and distance from the anus to the rear end (female) compared to specimens from ac 9 . The morphological analysis by light microscopy showed little variation in the level of bifurcations at the lateral rays in the right lobe of the copulatory bursa between the two haplotypes. The biological, morphological and morphometric variations observed between the two haplotypes agree with the observed variation at the molecular level using the cytochrome oxidase subunit I marker and reinforce the possible influence of geographical isolation on the development of these haplotypes.

Key words: Angiostrongylus cantonensis - Rattus norvegicus - haplotype - experimental infection - biology - morphology

Angiostrongylus cantonensis Chen, 1935 is a neurotropical nematode acquired primarily through ingestion of contaminated food. It was first reported parasitizing the pulmonary arteries and right heart ventricle of its main definitive hosts Rattus norvegicus and Rattus rattus in Guangzhou (Canton) China (Chen 1935, Wang et al. 2008, OuYang et al. 2012). This nematode has been recognised as the primary etiologic agent of hundreds of cases of human eosinophilic meningoencephalitis, whose clinical manifestation is eosinophilic meningitis (Alicata 1991, Wang et al. 2011, Cowie 2013). Humans can act as accidental hosts and become infected by eating raw or uncooked mollusks or food contaminated with infective L3 larvae (Martin-Alonso et al. 2011, Cowie 2013).

The major endemic regions where the presence of $A$. cantonensis was originally reported are Southeast Asia and Pacific Islands, but currently it is dispersed worldwide, including the Americas and Europe (Slom et al. 2002, Diaz 2008, Luessi et al. 2009, Carvalho et al. 2012, Thiengo et al. 2013). This zoonosis is considered an emerging infectious disease and its geographical expansion has been facilitated by the parasite's high ability to

doi: $10.1590 / 0074-0276130378$

Financial support: FAPERJ (E-100.525/2013), CAPES, CNPq

+ Corresponding author: maldonad@ioc.fiocruz.br

Received 13 August 2014

Accepted 27 November 2014 adapt to new intermediate invertebrate hosts (Hollingsworth \& Cowie 2006, Cowie 2013). The first human case of the disease was reported in Taiwan in 1945 (Beaver \& Rosen 1964) and since then more than 2,800 cases have been documented worldwide (Wang et al. 2011), including in Brazil, where human cases have been reported in the states of Espírito Santo (ES), Pernambuco (PE), São Paulo, Rio de Janeiro (RJ), Paraná and Rio Grande do Sul (RS) (Caldeira et al. 2007, Lima et al. 2009, EspíritoSanto et al. 2013, Morassutti et al. 2014).

In Brazil, $R$. norvegicus and $R$. rattus have been found naturally infected by $A$. cantonensis in the state of Pará (Moreira et al. 2013), the first species also having been found infected in ES (Caldeira et al. 2007), RJ (Simões et al. 2011) and more recently in RS (Cognato et al. 2013), confirming the parasite's endemicity. Different species of terrestrial gastropods and freshwater mollusks are involved in the lifecycle of $A$. cantonensis, acting as intermediate hosts. Mollusks such as Achatina fulica (Moreira et al. 2013), Bradybaena similaris, Subulina octona, Sarasinula marginata (Carvalho et al. 2012) and Pomacea lineata (Thiengo et al. 2013) have been reported naturally infected in the country.

Inter and intraspecific genetic variations in the genus Angiostrongylys have been reported using partial sequencing of the cytochrome oxidase subunit I (COI) gene (Jefferies et al. 2009), confirming its use as a molecular marker for differentiation of geographic isolates of $A$. cantonensis (Eamsobhana et al. 2010, Simões et al. 2011, Monte et al. 2012, Tokiwa et al. 2012). Three haplotypes of A. cantonensis (ac5, ac8 and ac9) have been reported in Brazil until now, considering the eight previously related 
(ac1-ac8) (Tokiwa et al. 2012). The ac8 haplotype is considered the most widespread, while the ac9 haplotype has been described only in Brazil (Monte et al. 2012).

The aim of this study was to compare biological, morphological and morphometric features of two Brazilian haplotypes of A. cantonensis (ac8 and ac9), characterised in a previous study, using the molecular marker COI.

\section{MATERIALS AND METHODS}

A. cantonensis haplotypes used - Two Brazilian A. cantonensis haplotypes were used in this study: haplotype ac8, obtained from naturally infected A. fulica collected in the municipality of Olinda, PE, which has been maintained in the laboratory using Biomphalaria glabrata and $R$. norvegicus (Wistar) at Pathology Laboratory, Oswaldo Cruz Institute/Oswaldo Cruz Foundation (Fiocruz), and haplotype ac9, obtained from naturally infected $R$. norvegicus rodents collected in Caju, a port district of the city of Rio de Janeiro, also maintained as described above. The collection permits for rodents were obtained from Fiocruz's Ethical Committee on Animal Use (permit LW-24/10) and the Brazilian government's Institute for Wildlife and Natural Resources (permit 24353-1).

The infected B. glabrata specimens were minced and artificially digested in a $0.7 \%$ hydrogen chloride solution for $2 \mathrm{~h}$ at $37^{\circ} \mathrm{C}$ (Wallace \& Rosen 1969). The digested samples were placed in a Baermman apparatus to recover L3 larvae by the Baermman-Moraes technique (Graeff-Teixeira et al. 1997). The recovered material was centrifuged for $10 \mathrm{~min}$ at $1,512 \mathrm{~g}$ and examined under a stereoscopic microscope (Zeiss MC80DX, Stemi SV6) to detect and count L3 larvae. The larvae were then inoculated by gavage in $R$. norvegicus.

Infectivity of $R$. norvegicus and elimination of L1 larvae in faeces - Five $R$. norvegicus (Wistar) rats per group were individually infected by gavage with $50 \mathrm{~L} 3$ larvae of each haplotype (ac8 or ac9) and then identified by staining the dorsal area with picric acid (identified as R1, R2, R3, R4 and R5). The prepatent period, number of L1 larvae released in faeces and the recovery rates of adult worms (male and female) for the two haplotypes were determined. From 35 days after infection, $1 \mathrm{~g}$ of faeces was collected daily from each rodent, infected with either haplotype, to evaluate the onset of L1 larvae elimination, using the Baermman-Moraes technique (Graeff-Teixeira et al. 1997). After this period, the faeces were collected every other day until the end of the assay (CEUA LW-24/10).

Ninety days after infection, the rodents were euthanised using a $\mathrm{CO}_{2}$ chamber and subsequently necropsied to recover adult helminths from the pulmonary arteries. The helminths recovered were counted and fixed in $93 \mathrm{~mL}$ of $70 \%$ ethanol, $5 \mathrm{~mL}$ of $37 \%$ formaldehyde and $2 \mathrm{~mL}$ of glacial acetic acid at $65^{\circ} \mathrm{C}$ (Amato et al. 1991) for morphological and morphometric analysis.

Morphological and morphometric analysis of adult helminths - Fifteen adult male and 15 female helminths of each haplotype (3 males and 3 females from each rodent) were randomly selected and the following characteristics were measured: body length and width, oesophagus length, distance from nerve ring to anterior end, distance from excretory pore to anterior end, length of spicule (male), length and width of gubernaculum (male), distance from vulva to tail (female) and distance from anus to tail (female). The specimens were clarified and mounted as temporary slides with lactophenol solution and examined under a light microscope. Drawings were made with the aid of a camera lucida attached to a Zeiss standard microscope. All measurements were made in millimetres.

Statistical analysis - The numbers of helminths recovered between haplotypes were compared using the Student $t$ test. The proportion between male and female specimens of each haplotype was compared using the chi-square test.

The intensity of infection was given by the median of L1 larvae from the weekly average of L1 larvae eliminated in $1 \mathrm{~g}$ of faeces using Mood's median test (Rózsa et al. 2000) with the Quantitative Parasitology 3.0 software (distributed by J Reiczigel, L Rózsa, 2005). The total number of L1 larvae eliminated in faeces between the seventh-12th weeks of infection was compared between haplotypes using the $t$ test. One-way analysis of variance (ANOVA) was used to determine weekly difference in the total number of L1 larvae eliminated for ac8 haplotype. The Kruskal-Wallis test was used for ac9 haplotype, since data on this haplotype were not normally distributed. Multiple analysis of variance was used to determine the difference in L1 larvae elimination between the two haplotypes between weeks.

ANOVA was used to compare the length of helminths recovered from rodents within each haplotype. The morphometric data were compared between haplotypes using the $t$ test. The Mann-Whitney $U$ test was used when data were not normally distributed. The total number of helminths recovered was correlated with helminth body length using Pearson's correlation to investigate the occurrence of overcrowding.

All data were tested for normal distribution using the Shapiro-Wilk test. The analyses were carried out using PAST v.2.10 (Hammer et al. 2001) and BioEstat v.5.0 (Ayres et al. 2007). Values with $p \leq 0.05$ were considered significant.

\section{RESULTS}

Biological analysis of the two haplotypes - All animals exposed to L3 larvae of each isolate were parasitised (Fig. 1). The prepatent period was similar for both haplotypes, ranging between $42-44$ days after infection. The parasitic burden recovered from rodents between the two haplotypes showed significant difference, with ac 9 haplotype showing higher number of helminths $(t=-2.779 ; p=$ 0.049 ) (Table I). A significant difference was observed between male and female specimens for ac9 haplotype $\left(\mathrm{X}^{2}\right.$ $=3.549 ; \mathrm{p}=0.05)$. However, for ac 8 , no significant difference was observed $\left(\mathrm{X}^{2}=0.252 ; \mathrm{p}=0.616\right)$ (Table I).

A progressive increase was observed in the number of L1 larvae eliminated in the faeces from the seventh to ninth and 10th week of infection for ac9 and ac8 haplotypes, respectively. In the following weeks, fluctuation was observed in the L1 larvae elimination for ac9, with a decrease after the 11th week. For ac8 haplotype, there was a slight continuous increase in larvae elimination un- 


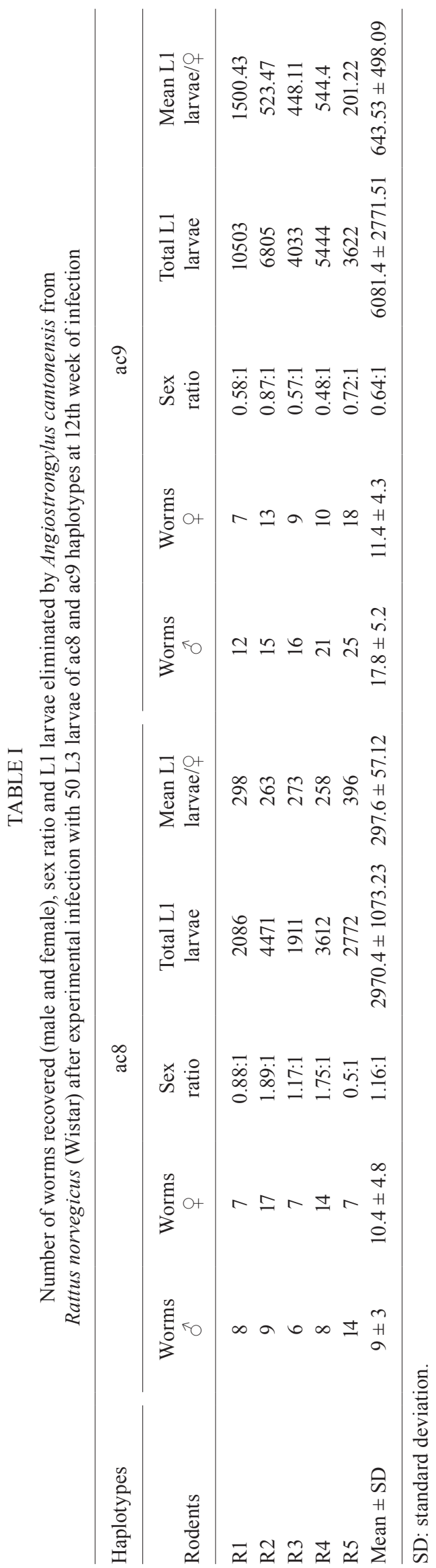

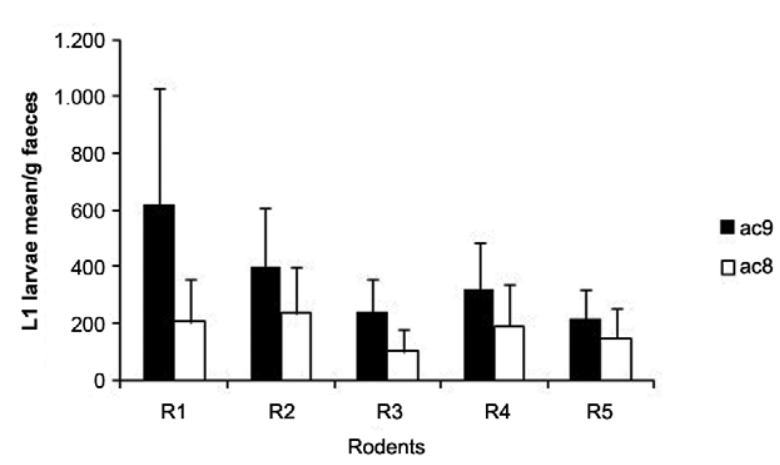

Fig. 1: mean \pm standard deviation of total L1 larvae eliminated of Angiostrongylus cantonensis per gram of faeces per individual Rattus norvegicus for ac8 and ac9 haplotypes from seventh-12th week after infection.

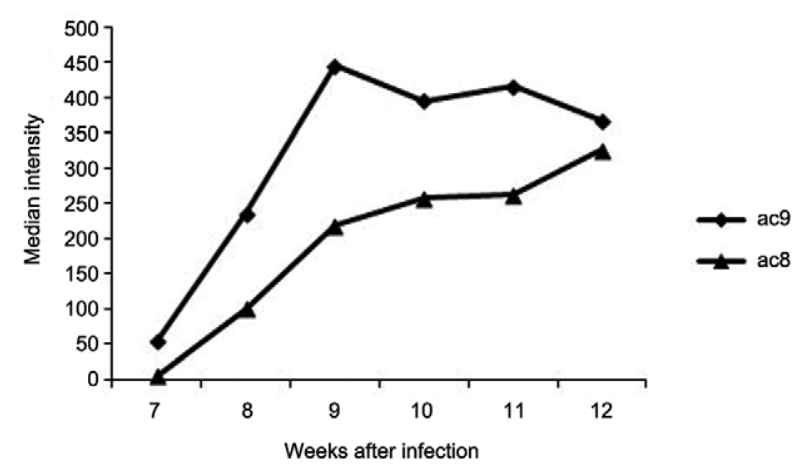

Fig. 2: intensity of infection for ac 8 and ac 9 haplotypes given by the median from the weekly mean of L1 larvae eliminated per gram of faeces.

til the end of the experiment, at the 12th week (Fig. 2). The difference in the L1 larvae elimination of each haplotype between weeks was also statistically significant with progression of the infection (haplotype ac9: $\mathrm{H}=15.73$; $\mathrm{p}$ $=0.0076$; haplotype ac8: $\mathrm{F}=14.08 ; \mathrm{df}=5 ; \mathrm{p}=1.772 \mathrm{E}-$ 06). The comparison of total L1 larvae eliminated showed a significant difference between the two haplotypes $(t=$ $-2.341 ; \mathrm{p}=0.047)$. We also observed a significant difference in L1 larvae elimination between the haplotypes when compared within weeks, which showed different profiles $(\mathrm{F}=8.66 ; \mathrm{gl}=5.48 ; \mathrm{p}<0.0001)($ Fig. 2 , Table I).

Morphometric analysis of adult helminths - There was no significant difference in the helminths' body length for each haplotype: male ac $8(\mathrm{p}=0.638)$, male ac9 $(\mathrm{p}=$ $0.947)$, female ac $8(p=0.282)$, female ac9 $(p=0.504)$ (Table II). Regarding the morphometric characteristics between the two haplotypes, there were significant differences in body length $(t=-8.758 ; p=4.7 \mathrm{E}-07)$, oesophagus length $(\mathrm{U}=41 ; \mathrm{p}=0.001)$ and spicule length $(\mathrm{t}=-2.115 ; \mathrm{p}$ $=0.05$ ) for male helminths. For females, we observed significant differences in body length $(t=-9.649 ; \mathrm{p}=1.452 \mathrm{E}$ $07)$, oesophagus length $(U=55 ; p=0.01)$ and the anustail distance $(\mathrm{U}=40 ; \mathrm{p}=0.002)$ (Table III). There was no significant correlation between the number of helminths recovered and the body length in either ac8 $(\mathrm{R}=0.736$; $\mathrm{p}$ $=0.156)$ or ac9 haplotype $(\mathrm{R}=0.129 ; \mathrm{p}=0.836)$. 
TABLE II

Mean \pm standard deviation of body length of adult worms ( 3 males and 3 females) of Angiostrongylus cantonensis from ac 8 and ac9 haplotypes recovered from each rodent after experimental infection

\begin{tabular}{|c|c|c|c|c|}
\hline \multirow{3}{*}{$\begin{array}{l}\text { Body } \\
\text { length }\end{array}$} & \multicolumn{4}{|c|}{ Haplotypes } \\
\hline & \multicolumn{2}{|c|}{ ac8 } & \multicolumn{2}{|c|}{ ac9 } \\
\hline & $\hat{\sigma}$ & q & 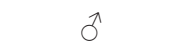 & q \\
\hline $\mathrm{R} 1$ & $24.9 \pm 1.54$ & $36.67 \pm 3.60$ & $20.57 \pm 2.23$ & $25.69 \pm 0.40$ \\
\hline $\mathrm{R} 2$ & $24.67 \pm 0.31$ & $32.13 \pm 1.01$ & $20.59 \pm 0.40$ & $27.69 \pm 0.34$ \\
\hline R3 & $25 \pm 1.47$ & $34.17 \pm 1.99$ & $20.07 \pm 1.56$ & $25.95 \pm 2.89$ \\
\hline $\mathrm{R} 4$ & $23.73 \pm 0.51$ & $33.53 \pm 3.15$ & $19.76 \pm 1.43$ & $25.99 \pm 1.01$ \\
\hline $\mathrm{R} 5$ & $24.93 \pm 1.21$ & $34.77 \pm 0.68$ & $20.38 \pm 1.18$ & $26.38 \pm 1.00$ \\
\hline Mean & $24.65 \pm 1.01$ & $34.25 \pm 2.09$ & $20.27 \pm 1.36$ & $26.34 \pm 1.13$ \\
\hline
\end{tabular}

TABLE III

Mean \pm standard deviation of adult worm characteristics (15 males and 15 females) of Angiostrongylus cantonensis from ac8 and ac9 haplotypes obtained after 12 weeks of experimental infection of Rattus norvegicus (Wistar)

\begin{tabular}{|c|c|c|c|c|}
\hline \multirow[b]{2}{*}{ Haplotypes } & \multicolumn{2}{|c|}{ ac8 } & \multicolumn{2}{|c|}{ ac9 } \\
\hline & $\hat{0}$ & 우 & $\pi$ & q \\
\hline Body length & $24.65 \pm 1.07$ & $34.25 \pm 2.54$ & $20.27 \pm 1.30$ & $26.34 \pm 1.44$ \\
\hline Width & $0.34 \pm 0.05$ & $0.41 \pm 0.05$ & $0.32 \pm 0.04$ & $0.42 \pm 0.06$ \\
\hline Oesophagus & $0.28 \pm 0.03$ & $0.3 \pm 0.02$ & $0.25 \pm 0.02$ & $0.28 \pm 0.02$ \\
\hline Nerve ring & $0.13 \pm 0.04$ & $0.14 \pm 0.04$ & $0.14 \pm 0.03$ & $0.15 \pm 0.03$ \\
\hline Excretory pore & $0.3 \pm 0.09$ & $0.32 \pm 0.05$ & $0.35 \pm 0.07$ & $0.32 \pm 0.06$ \\
\hline Spicule & $1.29 \pm 0.08$ & - & $1.23 \pm 0.09$ & - \\
\hline Gubernaculum & $0.05 \times 0.01$ & - & $0.06 \times 0.02$ & - \\
\hline Vulva-tail & - & $0.20 \pm 0.05$ & - & $0.19 \pm 0.02$ \\
\hline Anus-tail & - & $0.08 \pm 0.03$ & - & $0.06 \pm 0.02$ \\
\hline
\end{tabular}

Morphological analysis of adult helminths - The morphological analysis by light microscopy showed a slight variation at the level of bifurcations that unite the lateral rays of the copulatory bursa of male specimens. There were differences at the level of bifurcations of lateral rays $(4,5$ and 6$)$ in the right lobe of ac8 haplotype, while no differences were observed at the level of bifurcations of the same lateral rays for ac9. Variations were also observed in the ventral rays and dorsal rays between the two haplotypes. Specimens of ac 8 showed shorter and thinner ventral rays when compared with ac9 specimens and the dorsal rays of ac8 specimens were more prominent (Figs 3, 4).

\section{DISCUSSION}

Recent studies have demonstrated genetic variation in $A$. cantonensis using the COI gene as a molecular marker. According to these findings, nine haplotypes have been reported, although little is known about biological variation in these haplotypes (Monte et al. 2012, Tokiwa et al. 2012). Among these, the two haplotypes found in Brazil were used in the present study in order to investigate the presence of biological and morphological variability. The most important biological differences observed between these haplotypes were the total number of L1 larvae eliminated in faeces and the parasitic burden recovered, which was $60 \%$ for ac 9 haplotype and approximately $40 \%$ for ac 8 . These data corroborate the findings with $R$. norvegicus specimens infected with different Taiwanese strains of $A$. cantonensis, which showed adult recovery rates varying from $38-58 \%$ (Lee et al. 2014). In contrast, Au and Ko (1979) observed mean recovery rate of $82 \%$ after a small primary infection with $A$. cantonensis strain from Hong Kong, which was higher than that observed in the present study. These findings corroborate the molecular studies, indicating that different strains not only have genetic differentiation, but also different biological profiles.

In dioecious helminths, males and females do not always fit a 1:1 ratio. The number of female specimens may be favoured in small populations, but this trend can change if the intensity of infection increases, as observed in previous studies (Poulin 1997, D‘Ávila et al. 2012, Rishniw et al. 2012). Poulin (1997) analysed the 


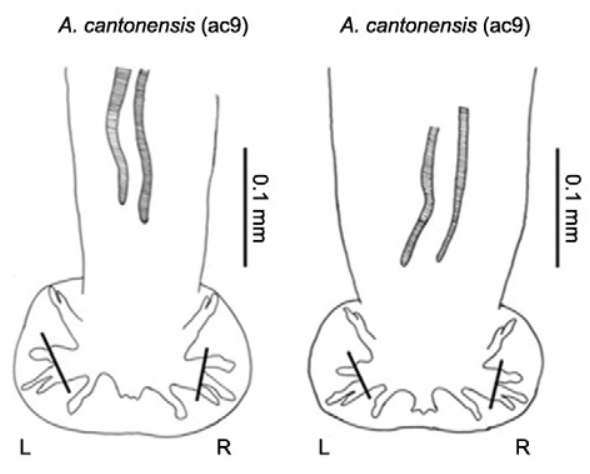

Fig. 3: light microscopy of Angiostrongylus cantonensis: dorsal view of caudal bursa from ac 8 haplotype and ac9 haplotype showing the differences in the level of bifurcations at the lateral rays (/). L: left; $\mathrm{R}$ : right. $\mathrm{Bar}=100 \mu \mathrm{m}$.
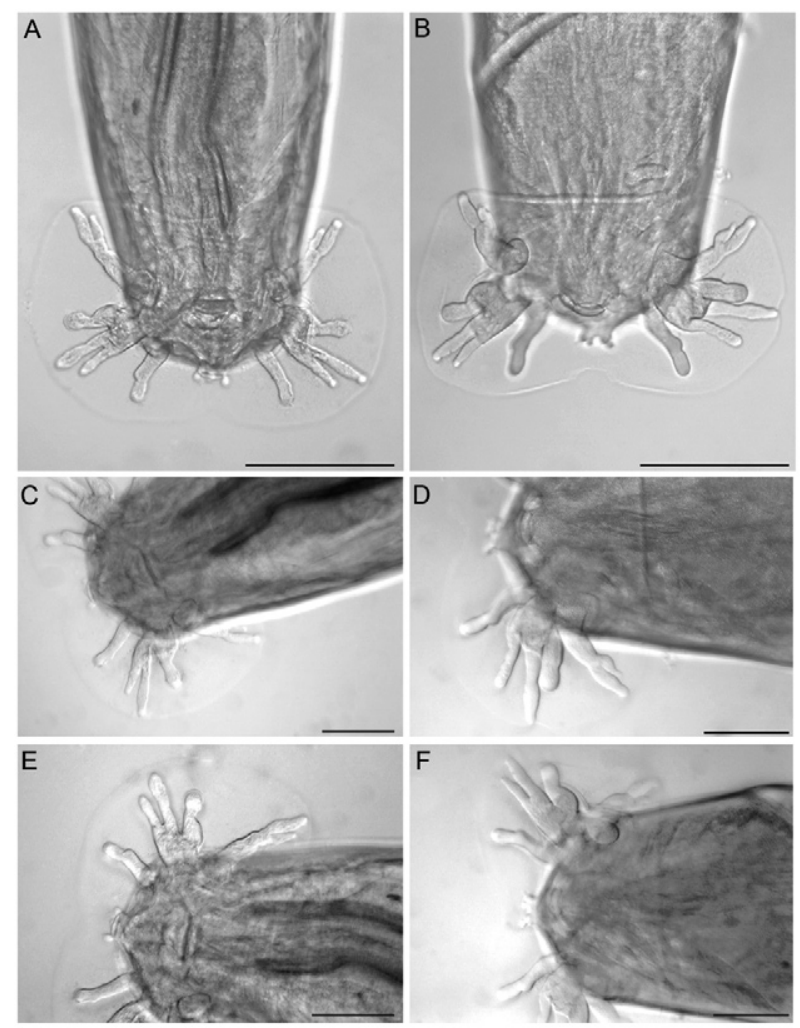

Fig. 4: light microscopy of Angiostrongylus cantonensis. A: ac8 haplotype; B: ac9 haplotype, dorsal view of caudal bursa; $\mathrm{C}$ : ac8 haplotype; D: ac9 haplotype, right lobe of caudal bursa; E: ac8 haplotype; F: ac9 haplotype, left lobe of caudal bursa. Arrows indicate the differences in the level of bifurcations at the lateral rays of caudal bursa. Bar $=50 \mu \mathrm{m}$.

relationship between sex ratio and intensity of infection in nematode species, observing a female bias in natural populations. Moreover, in experimental nematode populations, the intensity of infection was related with a larger number of adult male helminths. Confirming this assumption, in the present study the ac8 haplotype showed lower intensity of infection than ac9, with a larg- er number of females than males. The number of male specimens in ac9 haplotype was twice that of female specimens, with the number of females being similar between the two haplotypes. Besides this, the threefold higher number of L1 larvae eliminated in the faeces of ac9 haplotype suggests that the larger number of males may have increased the fertilisation of each female.

The morphological and morphometric analysis also showed differences in some characteristics, such as in copulatory bursa between the two haplotypes. In a previous study, Thiengo et al. (2010) compared the morphometry of adult helminths of two strains of A. cantonensis, from PE and Akita (Japan). The morphometric results found for the PE strain are in agreement with the results observed for ac8 haplotype for both males and females. The results of the morphometric analysis of adult helminths obtained for ac9 haplotype from Caju were similar to those observed in isolates from Akita, supporting the hypothesis that the parasite entered the country through trade with Asia (Monte et al. 2012).

Morphological and morphometric variations between different geographic isolates of $A$. cantonensis from Brazil were observed by Maldonado Jr et al. (2010). According to their results, the morphometric values found for the specimens from São Gonçalo and Barra do Piraí (RJ) were equivalent to those obtained for ac9 haplotype, with differences in the level of bifurcations at the lateral rays of the right copulatory bursa lobe, which were also observed for the specimens from Barra do Piraí, suggesting the possible presence of ac9 haplotype elsewhere in RJ, not just restricted to Caju. However, molecular studies are necessary to confirm this hypothesis.

In a recent study, Lee et al. (2014) observed, by molecular analysis and biological comparison of two strains of A. cantonensis, intraspecific variations of $19 \%$ and $11 \%$ for internal transcribed spacer gene and COI gene, respectively, despite differences in infectivity, fecundity and pathology. However, significant morphological differences were not observed, suggesting the possible occurrence of two cryptic species. Monte et al. (2012) showed that the intraspecific variation of the mtDNA sequence among the Brazilian isolates of $A$. cantonensis, related to ac8 and ac9 haplotypes, was $5.7 \%$, which is within the range expected for intraspecific variation (Blouin 2002). Although the haplotypes of the present study differed less than the isolates from Taiwan, it was possible to observe biological, morphological and morphometric differences between ac 8 and ac9 haplotypes, confirming that the observed variability at the molecular level corresponds to variability at the biological, morphological and morphometric levels within a species.

Differences observed among different strains of helminths may be related to geographic isolation (Maldonado Jr et al. 2005, Gharamah et al. 2012). The results obtained in this study for ac8 and ac9 haplotypes support this hypothesis, confirming that different Brazilian haplotypes identified by the molecular marker COI gene have different biological and morphological profiles. These haplotypes can be derived from different regions of Asia and may have remained isolated until now in Brazil. 


\section{ACKNOWLEDGEMENTS}

To Rodrigo Mexas, for the imaging service.

\section{REFERENCES}

Alicata JE 1991. The discovery of Angiostrongylus cantonensis as a cause of human eosinophilic meningitis. Parasitol Today 7: 151-153.

Amato JRF, Boeger WA, Amato SB 1991. Protocolos para laboratório - Coleta e processamento de parasitas e pescados, 1st ed., UFRRJ/Imprensa Universitária, Rio de Janeiro, 81 pp.

Au ACS, Ko RC 1979. Changes in worm burden, haematological and serological response in rats after single and multiple Angiostrongylus cantonensis infections. Z Parasitenkd 58: 233-242.

Ayres M, Ayres Jr M, Ayres DL, Santos AA 2007. BioEstat - Aplicações estatísticas nas áreas das ciências bio-médicas, Ong Mamiraua, Belém, 364 pp.

Beaver PC, Rosen L 1964. Memorandum on the first report of Angiostrongylus in man, by Nomura and Lin, 1945. Am J Trop Med Hyg 13: 589-590.

Blouin MS 2002. Molecular prospecting for cryptic species of nematodes: mitochondrial DNA versus internal transcribed spacer. Int J Parasitol 32: 527-531.

Caldeira RL, Mendonça CLGF, Gouveia CO, Lenzi HL, Graeff-Teixeira C, Lima WS, Mota EM, Pecora IL, de Medeiros AMZ, Carvalho OS 2007. First record of molluscs naturally infected with Angiostrongylus cantonensis (Chen, 1935) (Nematoda: Metastrongylidae) in Brazil. Mem Inst Oswaldo Cruz 102: 887-889.

Carvalho OS, Scholte RGC, de Mendonça CLF, Passos LKJ, Caldeira RL 2012. Angiostrongylus cantonensis (Nematode: Metastrongyloidea) in molluscs from harbour areas in Brazil. Mem Inst Oswaldo Cruz 107: 740-746.

Chen HT 1935. Un noveau nematode pulmonare. Pulmonema cantonensis, N.G., N sp. des rats de Canton. Ann Parasitol Hum Comp 18: 312-317.

Cognato BB, Morassutti AL, Silva AC, Graeff-Teixeira C 2013. First report of Angiostrongylus cantonensis in Porto Alegre, state of Rio Grande do Sul, southern Brazil. Rev Soc Bras Med Trop 46: 664-665.

Cowie RH 2013. Biology, systematics, life cycle and distribution of Angiostrongylus cantonensis, the cause of rat lungworm disease. Hawaii J Med Public Health 72: 6-9.

D‘Ávila S, Bessa ECA, Souza-Lima S, Rodrigues MLA 2012. Biased sex ratio and niche restriction in Baruscapillaria obsignata (Madsen 1945) (Nematoda, Capillariidae) from Columba livia (Aves, Columbidae). J Helminthol 86: 401-405.

Diaz J 2008. Helminth eosinophilic meningitis: emerging zoonotic diseases in the South. J La State Med Soc 160: 333-342.

Eamsobhana P, Lim PE, Solano G, Zhang H, Gan X, Yong HS 2010. Molecular differentiation of Angiostrongylus taxa (Nematoda: Angiostrongylidae) by cytochrome c oxidase subunit I (COI) gene sequences. Acta Trop 116: 152-156.

Espírito-Santo MCC, Pinto PLS, Mota DJG, Gryschek RCB 2013. The first case of Angiostrongylus cantonensis eosinophilic meningitis diagnosed in the city of São Paulo, Brazil. Rev Inst Med Trop Sao Paulo 55: 129-132.

Gharamah AA, Rahman WA, Siti Azizah MN 2012. Morphological variation between isolates of the nematodes Haemonchus contortus from sheep and goat in Malaysia and Yemen. J Helminthol 26: 1-7.

Graeff-Teixeira C, Medeiros E, Zanini GM, Brasil CAA, Cardozo BL, Dalpiaz MG, Bisol LW 1997. Inexpensive alternative material for the isolation of larvae with the Baermann method. Mem Inst Oswaldo Cruz 92: 399-400.
Hammer O, Harper DAT, Ryan PD 2001. PAST: Paleontological Statistics Software Package for Education and Data Analysis. Palaeontol Electronica 4: 9.

Hollingsworth RG, Cowie RH 2006. Apple snails as disease vectors. In R Joshi, L Sebastian (eds.), Global advances in ecology and management of golden apple snails, PhilRice, Muñoz, p. 121-132.

Jefferies R, Shaw SE, Viney ME, Morgan ER 2009. Angiostrongylus vasorum from South America and Europe represent distinct lineages. Parasitology 136: 107-115.

Lee JD, Chung LY, Wang LC, Lin RJ, Wang JJ, Tu HP, Wu ZD, Yen CM 2014. Sequence analysis in partial genes of five isolates of Angiostrongylus cantonensis from Taiwan and biological comparison in infectivity and pathogenicity between two strains. Acta Trop 133: 26-34.

Lima ARMC, Mesquita SG, Santos SS, Aquino ERP, Rosa LRS, Duarte FS, Teixeira AO, Costa ZRS, Ferreira MLB 2009. Neuroinfestation by Angiostrongylus cantonensis in Recife, Pernambuco, Brazil. Arq Neuropsiquiatr 67: 1093-1096.

Luessi F, Sollors J, Torzewski M, Muller HD, Siegel E, Blum J, Sommer C, Vogt T, Thomke F 2009. Eosinophilic meningitis due to Angiostrongylus cantonensis in Germany. J Travel Med 16: 292-294.

Maldonado Jr A, Simões RO, Oliveira APM, Motta EM, Fernandez MA, Pereira ZM, Monteiro SS, Torres EJL, Thiengo SC 2010. First report of Angiostrongylus cantonensis (Nematoda: Metastrongylidae) in Achatina fulica (Mollusca: Gastropoda) from Southeast and South Brazil. Mem Inst Oswaldo Cruz 105: 938-941.

Maldonado Jr A, Zeitone BK, Amado LA, Rosa IF, Machado-Silva JR, Lanfredi RM 2005. Biological variation between two Brazilian geographical isolates of Echinostoma paraensei. J Helminthol 79: 345-351.

Martin-Alonso A, Foronda P, Quispe-Ricalde MA, Feliu C, Valladares B 2011. Seroprevalence of Angiostrongylus cantonensis in wild rodents from the Canary Islands. PLOS ONE 6: 1-5.

Monte TCC, Simões RO, Oliveira AP, Novaes CF, Thiengo SC, Silva AJ, Estrela PC, Maldonado Jr A 2012. Phylogenetic relationship of the Brazilian isolates of the rat lungworm Angiostrongylus cantonensis (Nematoda: Metastrongylidae) employing mitochondrial COI gene sequence data. Parasit Vectors 5: 248.

Morassutti AL, Thiengo SC, Fernandez M, Sawanyawisuth K, Graeff-Teixeira C 2014. Eosinophilic meningitis caused by $A n-$ giostrongylus cantonensis: an emergent disease in Brazil. Mem Inst Oswaldo Cruz 109: 399-407.

Moreira VLC, Giese EG, Melo FTV, Simões RO, Thiengo SC, Maldonado Jr A, Santos JN 2013. Endemic angiostrongyliasis in the Brazilian Amazon: natural parasitism of Angiostrongylus cantonensis in Rattus rattus and $R$. norvegicus and sympatric giant African land snails, Achatina fulica. Acta Trop 125: 90-97.

OuYang L, Wei J, Wu Z, Zeng X, Li Y, Jia Y, Ma Y, Zhan M, Lei W 2012. Differences of larval development and pathological changes in permissive and nonpermissive rodent hosts for Angiostrongylus cantonensis infection. Parasitol Res 111: 1547-1557.

Poulin R 1997. Population abundance and sex ratio in dioecious helminth parasites. Oecologia 111: 375-380.

Rishniw M, Schukken Y, Greiner E 2012. Sex ratios of Dirofilaria immitis in naturally infected dogs show female bias at low worm intensities. Res Vet Sci 93: 1324-1328.

Rózsa L, Reiczigel J, Majoros G 2000. Quantifying parasites in samples of hosts. J Parasitol 86: 228-232.

Simões R, Monteiro F, Sánchez E, Thiengo S, Garcia J, Costa-Neto S, Luque J, Maldonado Jr A 2011. Endemic angiostrongyliasis, Rio de Janeiro, Brazil. Emerg Infect Dis 17: 1331-1333. 
Slom TJ, Cortese MM, Gerber SI, Jones RC, Holtz TH, Lopez AS, Zambrano CH, Sufit RL, Sakolvaree Y, Chaicumpa W, Herwaldt BL, Johnson S 2002. An outbreak of eosinophilic meningitis caused by Angiostrongylus cantonensis in travelers returning from the Caribbean. N Engl J Med 346: 668-675.

Thiengo SC, Maldonado A, Mota EM, Torres EJL, Caldeira R, Carvalho OS, Oliveira APM, Simões RO, Fernandez MA, Lanfredi RM 2010. The giant African snail Achatina fulica as natural intermediate host of Angiostrongylus cantonensis in Pernambuco, Northeast Brazil. Acta Trop 115: 1994-1999.

Thiengo SC, Simões RO, Fernandez MA, Maldonado Jr A 2013. Angiostrongylus cantonensis and rat lungworm disease in Brazil. Hawaii J Med Public Health 72: 18-22.
Tokiwa T, Harunari T, Tanikawa T, Komatsu N, Koizumi N, Tung K-C, Suzuki J, Kadosaka T, Takada N, Kumagai T, Akao N, Ohta N 2012. Phylogenetic relationships of rat lungworm, Angiostrongylus cantonensis, isolated from different geographical regions revealed widespread multiple lineages. Parasitol Int 61: 431-436.

Wallace GD, Rosen L 1969. Techniques for recovering and identifying larvae of Angiostrongylus cantonensis from molluscs. Malacologia 7: 427-438.

Wang Q, Lai D, Zhu X, Chen X, Lun Z 2008. Human angiostrongyliasis. Lancet Infect Dis 8: 621-630.

Wang QP, Wu ZD, Wei J, Owen RL, Lun ZR 2011. Human Angiostrongylus cantonensis: an update. Eur J Clin Microbiol Infect Dis 11: 1328-1335. 